\title{
A Case Study of English Language Learners in a Mobile Game-Assisted Environment During the Covid-19 Lockdown
}

\section{Ghulam Yasin}

Lecturer, Department of English, Govt. Alamdar Hussain Islamia College, Agahi Road, Multan, Punjab, Pakistan ghulam.yasin@scholars.usindh.edu.pk

\section{Asma Kashif Shahzad}

Assistant Professor, Humanities Department, COMSATS University Islamabad, Vehari Campus, Pakistan (Corresponding Author) asmashahzad@cuivehari.edu.pk

\section{Tahira Asgher}

Assistant Professor, Department of English Linguistics, The Islamia University of Bahawalpur, Pakistan.tahira.asgher@iub.edu.pk

\begin{abstract}
The research explores the motivational role of digital mobile games and the effect of anxiety/stress upon the participants during English Language Learning (ELL). Moreover, it also describes how the digital games develop the participants' interest and how these are helpful in ELL during the COVID-19 lockdown. It is the case study of three (03) English language learners with a secondary level of English proficiency, stuck at home due to COVID-19 lockdown in Pakistan. The participants were asked to play Spaceteam ESL, a digital mobile game that demands fluent oral exchanges of information. The participants played Spaceteam ESL in three (03) sessions, and every session consisted of an hour. Then the data was collected through the observation method and semi-structured interviews from the participants. Findings reveal that the participants' continuous responsive interaction during the game and the sense of not being judged by a teacher create a non-threatening and stress-free zone. It develops the participants' greater interest, becomes the ELL source, and has fun and killing time during the COVID-19 lockdown. The research is distinctive because its observations are based upon the outside classroom environment. In addition, it also finds the pedagogical utilisation and different features of Spaceteam ESL helpful in ELL.
\end{abstract}

Keywords: digital games, language teaching tools, English language learning, Anxiety, MALL

\section{Introduction}

The English language has become an international language in recent times. The people living in multicultural societies and with various linguistic backgrounds communicate through English. It is mostly happening after the remarkable development in technology (Alzeebaree\& Hasan, 2020). In most countries, the English language is now learned and used in formal or informal meetings inside or outside the classroom. Advanced technological apps like mobile phones make it very easy for people to grab required information, mainly in English, on their devices. Such ways of getting information are indirectly contributing to informal language learning. 
Further, ample usage of video games is also an essential factor in learning English. However, it varies from English Language Learning (ELL) activities because learning a language through such games is more significant than any other application. Qasim (2021) argues that "successful activities (games, internet, and blogging) [...] are superior to receptive behaviour" (p. 207).

Some studies describe that playing digital games for English Language Learning can be more beneficial for the students and learners (Schlasberg, 2020; Sundqvist, 2019; Jensen, 2017). Further, some studies present that the involvement of the Learners in learning through digital mobile games is more active; that is why such activities are known as learner-centred activities. In such cases, the role of a teacher is to encourage the learners for active and focused participation (Gozcu \& Caganaga, 2016; Ruliany \& Purnwarman, 2020).

The recognition of using video games in education has introduced digital game-based learning (DGBL). DGBL observes how digital games may be utilised in teaching and learning language. Among uncountable mobile apps and digital games, the study focuses upon using a single digital game Spaceteam ESL that can be easily played through mobile or computer for English Language Learning. Primarily it is used by the learners having English language competency of secondary level.

Concordia University researchers have developed Spaceteam ESL. They believe it is a "crazy and fun English learning game". This game is free for downloading because of the funding by Concordia University. Even the game also doesn't contain any ads. The game is started by a dial found in the middle of the screen. Moreover, it also has three options, "about, settings and practice," which assist the users to play this game. Further, its website also provides "technical instructions, lesson plans and the option for teachers to create a custom lexicon". It may help enhance or control the activities to be performed (Valdimarsson, 2020, p. 38).

\section{Significance of Digital Games in ELL}

Many mobile applications help the students in English Language Learning. It has become unavoidable now because the development of technology has affected every field of life. The digital world now demands learners to utilise this technology and improve their skills (Ruliany \& Purnawarman, 2020). In addition, this development also requires that English teaching methods should also be upgraded. It is because mobile applications have got a vital 
place and also support ELL context for the learners. These games also keep the learners involved where:

- $\quad$ "The players are encouraged to take risks and explore new things".

- $\quad$ "The players have the opportunity to customise the game, so take the decision".

- $\quad$ "Games increase motivation and desire for self-improvement".

- $\quad$ "Games develop students' ability to observe".

- $\quad$ "Games facilitate collaborative learning".

(Gee, 2008, p. 318; Henry, 2013, p. 10; Gozcu \& Caganaga, 2016, p. 125).

\section{Literature Review}

Mobile phone games motivate the learners to use language learning inside or outside the classroom (Egbert \& Neville, 2015). The real advantage is that the usage of digital games is the source of enhancement in the learners' results (Green, 2016). The use of mobile phones is more accessible in different environments of the learning class. It shows that mobile phones and various digital devices may boost language learning (Kessler \& Hubbard, 2017). Digital games in English learning provide students several opportunities to keep them indulged and bring forth better results in speaking and writing (Jensen, 2017). Digital games give students a chance to communicate with their fellow players, and it is a vital source for learning the English language (Sundqvist, 2019).

The language teachers must be familiar with the digital games being useful in language learning and how such games may be utilised in this context of education (Schlasberg, 2020). The use of video games is different from other extramural English practices because these games are the source of effectively utilising the language and produce a better outcome in learning than the other applications (Qasim, 2021). The students need to be well known about the culture of technology. It is vital because learning a language through technology assists the methods of teaching and learning and mobile phone applications are the more significant source of it (Ruliany \& Purnawarman, 2021). Mobile phones and technology have provided access to information in bulk to the common person as well. Being the reason for developments in every field, technology has also benefited all educational areas and language learning (Berry, 2021).

Some particular mobile games like Spaceteam ESL helps improve English as a second language for the learners and enhance the learners' oral fluency (Grimshaw \& Cardoso, 2018). The mobile game, Spaceteam ESL, assists the learners in improving their verbal fluency (Grimshaw\& Cardoso, 2018), and further, it also keeps them engaged in ELL classrooms 
(Cardoso et al., 2015). In addition, mobile games like Spaceteam ESL provide learners with good opportunities to use and improve their language skills (Berry, 2021).

Along with countless advantages, some researchers also point out some drawbacks to using mobile games in the field. The excessive playing digital games on mobile phones are also becoming the cause of some mental disorder of the students because the most common factor for increasing such disorders is the ample use of mobile phones and digital games (Shabalina et al., 2020). Further, the continuous play of digital games can cause some physical damages like "Nintendo thumb, epileptic seizures, and joint, muscles, and skin problems". It may also make the children addicted and negatively impact their studies (Siahpoosh \& Ilkhani, 2020, p. 3).

\section{Digital mobile Games/Apps Selection for English Language Learning (ELL)}

Mobile phones are used in greater numbers throughout the modern world. Such devices have connected people with information technology that have been beneficial to the educational sector as well. According to Kessler \& Hubbard (2017), digital devices contain various features, and mobile phones are far more versatile and easily accessible for learners. Green (2016) also argues that mobile phones and other digital devices connecting with information technology may be utilised in language learning.

Students love to play mobile games only for having fun alone or among friends, but the language teachers must have a reason to recommend them a game for playing. In this regard, their concerns with the acquired syllabus and textbooks involved in ELL should be focused. Some researchers (Gozcu \& Caganaga, 2016, p. 125; Gamlo, 2019, p. 51) put forward various suggestions regarding the selection of Mobile Games.

- $\quad$ "Games should be used to motivate the students but not for fun".

- $\quad$ "By using such games, the students should learn, practice, or refresh language components".

- $\quad$ "Games should be in accordance with students' age and level of knowledge".

- $\quad$ "Short-time games should be used; otherwise, students may lose their interest".

Games Used for the Learners of Secondary level in ELL

Gangaiamaran \& Pasupathi (2017) have introduced different mobile games and apps being used in English language learning. They have also classified these digital games at the levels of learners like primary, secondary and tertiary levels. Though many digital/Mobile 
games are used while considering the need and interest of the learners in ELL, the researchers have selected only three of them with some details given below.

Knudge.me: it is the project of Knudge Technology Private Limited. The app chiefly deals with vocabulary acquisition by using flashcards for the purpose. The free download option is available, but a subscription is required if the user wants to utilise all its contents (Valdimarsson, 2020, p. 38).

Learn English Grammar: British Council has developed this app for English learners. It may also be downloaded for free, but it contains some advertisements for generating some income. Practice and Test are two modes of the app. There are exercises of different levels in the practice section, and the test section consists of tests for checking the learners' language skills. (Kukulska-Hulme, Norris and Donohue, 2015, p. 37)

World of Warcraft: it is an online Role-Playing Game that many players can play. Even the players in thousands may be linked together. The Players use their skills and information against the monsters, or two groups may also fight against each other (Henry, 2013, p. 8).

\section{Research Methodology}

The present study is a qualitative case study. The researchers utilised semi-structured interviews and observation methods to collect data. The justification for selecting a case study is that the researchers intend to have a more profound understanding of the lives of the chosen participants so that valuable and original data may be attained. According to Gozcu \& Caganaga (2016), the case study research is an empirical analysis that enquires some happenings of the day "within its real-life context; when the boundaries between phenomenon and context are not evident" (p. 130). Further, qualitative research provides detailed information through flexible enquiries or close observation of the happenings regularly (Debreli, 2012; Berry et al., 2021; Koşar, 2021).

The study also examines the impact of the Spaceteam ESL game on the students learning English who are stuck at home because of the COVID-19 (third wave) lockdown in the city. They are not attending any preparatory class for this purpose. So, the data collected through qualitative instruments has been preferred. According to Cohen et al. (2013), interviews, observations, and games are popular tools for collecting qualitative data.

Additionally, the research neither aims to generalise the findings at some broader level, nor the researchers are desired to compare the statistical data. Still, its purpose is only to bring 
forth some details through the limited number of participants. Therefore, the qualitative research design is more suitable for the study. The details regarding data collecting tools are given below:

\section{Semi-Structured Interviews}

Semi-structured interviews have been conducted for the purpose, and the reason behind this is to attain detailed and in-depth understandings regarding the behaviours and perceptions of the interviewees. Further, the rationale behind adopting this strategy is to explore the factors like opinions and perceptions of the students(Mackey \& Gass, 2005; Zemni \& Alrefaee, 2020). These interviews aim to reveal the students' views regarding learning English while playing the game Spaceteam ESL.

\section{Mobile Digital Game: Spaceteam ESL}

The second tool used to collect data is Spaceteam ESL, a digital video game. This digital game is simply played by two or three players easily. Importantly, all the players have to sit together at the same place, and every player must have their own device (mobile phone/computer). Right from the beginning, it demands sharing and communication of the players to go ahead together in the game. The players remain involved in playing the game and share the information and instructions loudly with the other fellows. It is done repeatedly. All the partners pay heed to the message of other fellows and then perform to move forward in the game. In case of failure by any partner, the ship in the game begins to lose its power and finally, it is destroyed. So listening or receiving the message accurately and efficiently is essential for every player playing this game. This practice demands every player to speak accurately and loudly so that the other players may understand it quickly and then follow the instructions.

The rationale behind choosing this particular Spaceteam ESL mobile game is because it demands excellent communication among all the participants. Moreover, it also requires fewer participants as this case study consists of only 03 participants. In addition, this "entertainment-oriented mobile game" also possesses a unique educational feature that consists of a "customisable lexicon" (Berry et al., 2021, p. 4). Its lexicon may be customised for every single game to be observed by the researchers. The researchers may arrange its settings and may change the required and particular vocabulary to the game. After the modification, students have no other options despite using the vocabulary assigned to the game during the process. 
Further, the game is also helpful in improving listening and speaking skills in English Language Learning. The players of the game are required to listen and then speak to each other. There is also an option of "Practice" in the game. All the participants may also practice for correct pronunciation of the words to be used in the game. All the participants must play this game while sitting in the same room (Valdimarsson, 2020, p. 39).

\section{Observation}

Observation methods are always helpful in observing nonverbal expressions, and the researchers focus upon the feelings and communication among the participants. Further, this method also assists in knowing how the participants interact with one another and how much time they spend in some particular activity. The observations are also helpful in understanding the reactions or ideas that the participants wouldn't share at the interview. According to Mashori (2007), the data collected through observation also supports "the findings elicited from other data sets" (p. viii).

The rationale behind selecting observation methods is explicit that the researchers are desired to have a cross-check of the attitudes and feelings of the participants with the results of their interviews. For this purpose, the researchers had spent 03 hours with the participants when they were also busy playing Spaceteam ESL games on their mobile phones and has tried to observe them deeply.

\section{Participants' Selection for Collecting Data}

Cohen et al. (2013) demand to consider four elements at the time of sampling: size, representativeness, access, and strategy. The researchers also believe the mentioned elements to explore things in detail through interviews.

The researchers have invited 12 students between the ages of 10-20 to participate in the research. They all were not going to school for the last 40 days because of the third wave of COVID-19 lockdown. Further, it was also not possible for the researchers to access any particular class in the school for the same reason. Additionally, 09 out of 12 participants are either unwilling to participate or their parents do not allow them due to the pandemic. Therefore the researchers have designed the qualitative research dealing with a small number of participants. Furthermore, it deals with the varied sample of 03 participants with 02 boys and 01 girl to collect data. 
The research has opted for criterion-based sampling while considering the COVID-19 (Third-wave in Pakistan) conditions. The self-made criterion by the researchers defines what characteristics, in general, the participants must possess, it is mentioned below:

- It is not mandatory if the participants are students of any particular class or school dealing with English Language Learning.

- English proficiency level of the participants should not be less than secondary level.

The final selected participants do fulfil the above-given conditions. Their age group (12-16 years) and their proficiency in English learning are of secondary level. According to Gangaiamaran \& Pasupathi (2017), the students having "age group 12-17 belong to the secondary level of learners" (p. 11245). Further, they are also not attending any school or class for ELL.

Information regarding the participants is as under in Table 1:

\begin{tabular}{|l|l|l|c|}
\hline $\begin{array}{l}\text { Name of the } \\
\text { participants }\end{array}$ & Age & Level of Education & Nationality \\
\hline Ahmad Umer & 16 years & Secondary level & Pakistani \\
\hline JaveriaYasin & 14 years & Secondary level & Pakistani \\
\hline Muhammad Ali & 12 years & Secondary level & Pakistani \\
\hline
\end{tabular}

Table 01

\section{Data Collection Process}

To collect data, 03 selected participants played Spaceteam ESL using their mobile phones. The participants played this game 03 times in the second week of May 2021 while sitting in the same room. The duration of every time was 01 hour, and it took 03 hours. The researchers arranged the particular settings for playing the game with a specific purpose while considering SOPs of COVID-19 conditions.

During these three meetings in a week, the researchers observed the participants closely. The researchers also conducted further interviews with the participants at the end of the week. All three participants attended the session of interviews, and it continued for about one hour. The researchers have opted questionnaire because it is "less time-consuming and reduces researchers bias to some extent" (Syed. G, 2020, p. 475). The participants asked the following 04 questions:

- How do mobile games motivate you in English Language Learning? 
- Do you feel anxiety/stress during Spaceteam ESL mobile game playing at research time?

- How engaging was the mobile game to play to learn the language?

- Do you believe that playing mobile games at home during COVID-19 lockdown is helpful in English Language Learning?

The questionnaire was designed based on previous questionnaires (Berry et al., 2021, Gozcu \& Caganaga, 2016). These previous questionnaires have also been beneficial in enquiring the behaviours of the students towards English Language Learning through the use of Mobile games.

\section{Analysis of the Data Collected}

\section{Mobile Games as the Source of Motivation in ELL}

The data collected describes that learning through Spaceteam ESL is the source of creating fun and satisfaction. The responses of the participants regarding the question, "How do mobile games motivate you in learning the English Language"? are found as given; "the game is full of fun along with learning new words" (interviewee, Ahmad Umar). The next participant also comments, "first listening and then responding to the co-player motivates me for improving language" (interviewee, JaveriaYasin). The last participant Muhammad Ali also loves this game because "the game is really enjoyable and I would like to play it many times".

The researchers also observe that all three participants remain involved with a high level of interest and are found somehow curious about the following message of their fellow players. So this activity motivates the participants to learn new English language words and improve their listening and speaking skills. According to Lan (2014), The prime advantage of video games language learning is that their usage motivates the learners effectively.

The findings are also parallel to the various studies (Gamlo, 2019; Lin et al., 2018; Cam and Tran, 2017) in this field. Lin et al. (2018) utilise a mobile application in group research, bringing better results in learning ELL. Further, playing the game is also the source of rising motivation. Most of the participants have found this process easy, exciting and beneficial for the purpose. Cam and Tran (2017) utilise mobile game applications to teach English grammar and conclude that it assists the learners more effectively in learning grammar and language.

\section{Feeling Lower Anxiety and Stress}

Learners sometimes suffer because of the unknown words in the process of ELL and begin to feel anxiety and stress. Further such feelings create discomfort, which also influences 
the process of learning. In this regard, Gozcu \& Caganaga (2016) find that "Games assist in decreasing anxiety, feeling comfortable, and wanting to learn more" (p. 133). It is because playing games is learning with fun which keeps the participants relaxed. In addition, the participants know that the purpose is only to communicate or convey the message. They don't feel worried about mistakes of any kind.

In response to the question "Do you feel anxiety/stress during Spaceteam ESL mobile game playing at research time"? Javeria Yasin, being the participant, claims that "I was never under stress because I wasn't thinking about my mistakes". According to Muhammad Ali, "My anxiety was decreasing all the time with the increasing level of interest; I also enjoyed the use of different new words I was learning in the process". Furthermore, Ahmad Umar also exclaims, "I never felt any stress because I was aware of not being criticised by the participants or by any other in case of committing any mistake".

It is observed that the participants were relaxed and comfortable in using language, and they were not feeling any hindrances or hesitation in communicating with other participants. It was due to their interest in playing mobile games. The utilisation of mobile games in ELL is the source of encouragement and helps the participants avoid feelings of anxiety and stress. Moreover, many foreign language learners suffer from anxiety because of the fear that they have inadequate pronunciation. However, if stress-free settings are provided to the students in language learning, their anxiety level is reduced (Berry, 2021).

\section{Digital Mobile Games as an Interesting Source of Learning}

In response to the third question, "How interesting was the mobile game to play to learn a language?" all the participants found it an exciting way of learning language and showed their determination to keep learning language through such applications during their stay at home because of COVID-19 lockdown. The participant Ahmad Umar found this game-play "very interesting and helpful because it engages in interaction with other fellows all the time". JaveriaYasin also found learning a language through mobile games "an easy and learning language without any feelings of boredom".

The findings of some researches also relate to the observations of the present analysis. Zain (2021) finds that learning through mobile games keeps the students engaged in continuous interaction, reduces the number of demotivated factors, and help in achieving the learning tasks. Reynolds and Taylor (2020) also reveal that this mode of learning promotes active participation and the participants learn language by having fun and enjoyment. 


\section{Mobile Games as the Source of ELL During COVID-19 Lockdown Situation}

During the COVID-19 lockdown, the students remained stuck at their homes in different periods. In response to the question, "Do you believe that playing mobile games at home during COVID-19 lockdown is helpful in English Language Learning?" The participant Ahmad Umar claims that "I have learnt many new words with the help of mobile apps, and it also develops my interest every time". Muhammad Ali argues that "learning through mobile games was very interesting and it remained useful in learning the English language". Furthermore, JaveriaYasin also mentions that "learning English with the help of mobile games was never boring; it helped her in positively killing the COVID time".

The research also observes that the students love to play mobile games during their stay at home. They keep them involved in playing games as individual players or sometimes develop an online group of two or more players belonging to different communities. This sort of interaction through mobile games helps learn the English language.

Qasim (2021) argues that video games offer the learners suitable settings to interact with one another, the reason why these have a vital role in ELL. Digital games also provide a learner-centred environment and enhance the chances for interaction. Digital mobile games offer a multimedia context where the ELL learn vocabulary and key sentences. They also interact regularly, which help them in language learning (Siahpoosh \& Ilkhani, 2020). The interest in using mobile technology has developed greater in this era. This use of technology and playing digital games bring improvement in the learning language of the children. Digital games produce an environment of learning where the players work collectively and cooperate in the process of learning (Derakhshan \& Khatir, 2015).

\section{Suggestion For Future Research}

Mobile devices are an essential part of our modern daily life. Having access to different apps, the students decide what and how they learn things. They choose other digital games and apps to learn a language. Most of the research conducted in this field has worked upon online digital games where the use of the internet is essential. Still, there is a considerable research gap to inquire about offline mobile apps. Such research would help the underdeveloped countries and areas that cannot afford mobile games/apps effectively for English Language Learning. 


\section{Conclusion}

Learners' sense from digital mobile games is that learning language is an implicit element and fun. Such games also develop an emotional attachment, promoting English Language Learning. The digital games keep the participants engaged by creating motivational feelings, which forces them to complete the task. This motivational force and continuous interaction with the other participant are the authentic sources of improving language learning.

Most of the studies reviewed were conducted in the classroom, but the present study is based outside the school. Spaceteam ESL contains several features that encourage English language learning. It provides the learners with opportunities for learning and oral practising of new words. It also demands the immediate response of other participants (listeners). The data collected suggests that the game-play also decreases the participants' anxiety that might have been faced while learning a new language. The participants felt more comfortable using the English language, and continuous responsive interaction with other participants provided suitable learning conditions. Further, the sense of not being judged by a teacher or other participants also created a non-threatening and comfortable zone. These elements collectively contribute to developing an environment where the participants have high interest, fun, and motivation to learn a new language.

\section{References}

Alzeebaree, Y. \& Hasan, I. A. (2020). What makes an effective EFL teacher: High School Students' Perceptions. Asian ESP Journal, 16 (2), 169-183.

Berry, D, M. (2021). Level up Your Pronunciation: Impact of a Mobile Game. MEXTESOL Journal, 45(1), 1-12.

Cardoso, W., Grimshaw, J., \& Waddington, D. (2015). Set super-chicken to 3! Student and teacher perceptions of Spaceteam ESL. Critical CALL-Proceedings of the 2015 EUROCALL Conference, Padova, Italy, 102-107. https://doi.org/10.14705/rpnet.2015.000317

Cam, L., \& Tran, T. T. M. (2017). An evaluation of using games in teaching English grammar for first year English-majored students at Dong Nai Technology University. International Journal of Learning, Teaching and Educational Research, 16(7), 55-71.

Cohen, L., L. Manion and K. Morrison (2013) Research Methods in Education. 7th ed. London: Routledge. 
Debreli, E. (2012). Change in beliefs of pre-service teachers about teaching and learning English as a foreign language throughout an undergraduate pre-service teacher training program. Procedia Social and Behavioral Science, 367-373.

Egbert, J., \& Neville, C. (2015). Engaging K-12 language learners in media literacy. TESOL Journal, 6(1), 177-187. https://doi.org/10.1002/tesj.182

Derakhshan, A., \& Khatir, E. D. (2015). The effects of using games on English vocabulary learning. Journal of Applied Linguistics and Language Research, 2(3), 39-47.

Gamlo, N. (2019). The Impact of Mobile Game-Based Language Learning Apps on EFL. English Language Teaching, 12 (4), 49-56. https://doi.org/10.5539/elt.v12n4p49

Gangaiamaran, R., \&Pasupathi, M. (2017). Review on use of mobile apps for language learning. International Journal of Applied Engineering Research,12(21), 1124211251.

Gee, J. P. (2008). Game-like learning: An example of situated learning and implications for opportunity to learn. Assessment, Equity, and Opportunity to Learn. New York: Cambridge University Press. P. 200-21.

Gozcu, E. \& Caganaga, C., K. (2016). The importance of using games in EFL classrooms. Cypriot Journal of Educational Science. 11(3), 126-135. http://sproc.org/ojs/index.php/cjes/

Green, A. (2016). Significant returns in engagement and performance with a free teaching app. The Journal of Economic Education, 47(1), 1-10. https://doi.org/10.1080/00220485.2015.1106359

Grimshaw, J., \& Cardoso, W. (2018). Activate space rats! Fluency development in a mobile game-assisted environment. Language Learning \& Technology, 22(3), 159-175. https://doi.org/10125/44662

Grimshaw, J. (2016). Activate space rats! Mobile gaming and L2 pronunciation. Masters thesis, Concordia University.

Henry, A. (2013). Digital games and ELT: Bridging the authenticity gap. In E. Ushioda (Ed.). International perspectives on motivation: Language learning and professional challenges. 133-155. 
Jensen, S. H. (2017). Gaming as an English Language Learning Resource among Young Children in Denmark. CALICO Journal, 34(1), 1-19. https://files.eric.ed.gov/fulltext/EJ1143385.pdf

Kessler, G., \& Hubbard, P. (2017). Language teacher education and technology. In C. A. Chapelle\& S. Sauro (Eds.), The handbook of technology and second language teaching and learning (pp. 278-292). Wiley-Blackwell.

Koşar, G. (2021). Distance Teaching Practicum: Its Impact on Pre-Service EFL Teachers' Preparedness for Teaching. Special Issue: COVID-19: Education Response to a Pandemic, 9 (2), 111-126.

Kukulska-Hulme, A, Norris, N, \& Donohue, J. (2015). Mobile pedagogy forEnglish language teaching: a guide for teachers. UK: British Council.

Lan, Y.-J. (2014). Does Second Life improve Mandarin learning by overseas Chinese students? Language Learning \& Technology, 18(2), 36-56. http://dx.doi.org/10125/44365

Lin, Y.-T., Tseng, Y.-M., Lee, Y.-S., Wang, T.-C., Tsai, S.-I., \& Yi, Y.-J. (2018). Development of a SoLoMo Game-Based Application for Supporting Local Cultural Learning in Taiwan. Educational Technology \&Society, 21(4), 115-128.

Mackey, A., \& Gass, S. M. (2005). Second Language Research. Routledge.

Mashori, G. M. (2007). Teaching the Writing of English: Exploring the Impact of Process Approach on the Undergraduate Students of Shah Abdul Latif University Khairpur. (PhD dissertation). Shah Abdul Latif University Khairpur, Pakistan.

Qasim, A. (2021). Impact of Digital Games on Incidental Vocabulary Acquisition of Pakistani High School Students. Asian EFL Journal, 28 (1), 206-224. https://www.researchgate.net/publication/349334628

Reynolds, E. D., \& Taylor, B. (2020). Kahoot!: EFL instructors' implementation experiences and impacts on students' vocabulary knowledge, CALL-EJ. 21(2), 70-92.

Ruliany, S. \& Purnawarman. (2020). Teacher's Perception of Mobile Game-Based Assessment in ELT Context. ICOPE, 1-13. https://doi.org/10.4108/eai.16-10-2020.2305189

Schlasberg, F. (2020). The Effectiveness of Digital COTS Games for EFL learners' Vocabulary Acquisition. Thesis. Malmo University.

Shabalina, O., Davtian, A., Khvastunova, E., \& Moffat, D. C. (2020). Developing Mobile Games that Enables Young Adults, with Severe Mental Disorder, to Learn Everyday 
life skills Enjoyably. In European Conference on Games Based Learning. (p. 530XVII). Academic Conferences International Limited.

Siahpoosh, H., \& Ilkhani, S. (2020). On Digital Games and Their Promise for the Development of Knowledge of English Phrasal Verbs. Specialty Journal of Language Studies and Literature, 4(2), 1-13.

Sundqvist, P. (2019). Commercial-off-the-shelf games in the digital wild and L2 learner vocabulary. Language Learning \& Technology, 23(1), 87-113. https://scholarspace.manoa.hawaii.edu/bitstream/10125/44674/1/23_01_1012544674.pdf

Syed, G. K. (2020). Citizenship through Fiction: An Insight into Pakistani Undergraduate Students' Perceptions. Asian Journal of Social Science,48(5-6), 468-487. http://doi.org/10.1163/15685314-04805006

Valdimarsson, S. M. (2020). English Language Learning Apps: A Review of 11 English Language Learning apps. Thesis. Hungvisindasvid: University of Iceland. http://hdl.handle.net/1946/36956

Zain, D. S. M. (2021). Mobile-Assisted Language Learning (MALL) for Higher Education Instructional Practices in EFL/ESL Contexts: A Recent Review of Literature. Computer Assisted Language Learning Electronic Journal, 22(1), 290-317.

Zemni, B. \& Alrefaee, Y. (2020). Investigating the Source of Reading Anxiety among Undergraduate Saudi Female EFL Students in Translation Departments. TESOL International Journal, 15 (5). 65-77.

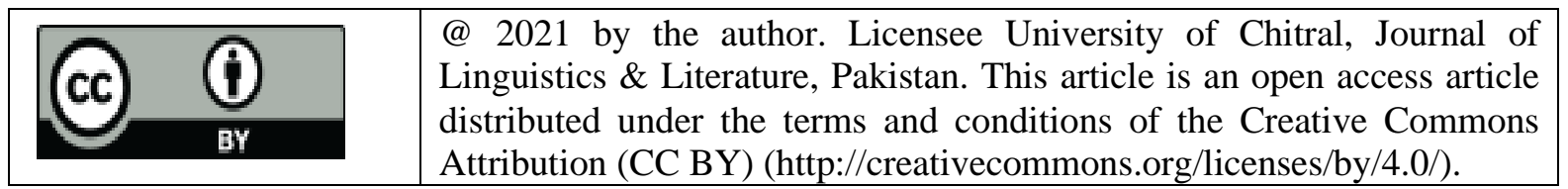

